\title{
Application of Erlang Queuing Model in Process of Airport Security Check
}

\author{
Huayanran Zhou ${ }^{1, \text { a }}$ \\ ${ }^{1}$ School of North China Electric Power University, Hebei 071000, China \\ a364876093@qq.com
}

Keywords: Queuing theory, Erlang queuing model, Air transportation, Security check process, Bottlenecks.

Abstract. Since the current way of airport security check requires a couple of time to complete. To identify the main points where problems exist in the current process, analyze the performance and parameters of Erlang queuing model, and give its scope of the application in process of airport security check. Then, establish a Single-Channel multi service window Erlang queuing model to explore the flow of passengers and find out the bottleneck.

\section{Introduction}

Application of queuing model in process of airport security check already has a long history, but much more is on the research of the ideal state or special status, assuming that each customer's arrival time are independent of each other, and obey the negative exponential distribution. The negative exponential distribution is a form of degradation of Erlang distribution, but actual passenger flow situation is more complicated.

This article will focus on research queuing system application in the passenger terminal passenger flow analysis when customers arrived in time interval to Erlang distribution. Taking Chicago O'Hare Airport as an example, study on the flow of aviation passengers passing through a security check point and its bottlenecks, therefore identify the main points where problems exist in the current process.

\section{Queuing Model}

\section{Concept.}

Queuing model is a probabilistic model, which includes the process of renewal and birth and death but more complex. The simple queuing process is formed under the action of two independent flows--- one is the "customer flow" which refers to passengers' waiting time, the other is "time flow" which means the time begin with the customers entering the service line and stop at the point the inspection service is completed. Customers are assumed to arrive one by one, and the time intervals from an update stream. The general process of queuing system is shown in Fig. 1.

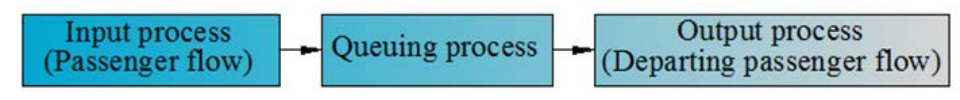

Fig. 1 Block diagram of queuing system

\section{Multi-service Windows Single Queue Waiting Queuing Model.}

The system has a number of service windows while the passengers are waiting in a unique queue. Customers can go to any of the windows and accomplish the process. Once the service window is empty, the first passenger in the waiting queue can go directly to the window to accept service, which can be seen in Fig. 2. 

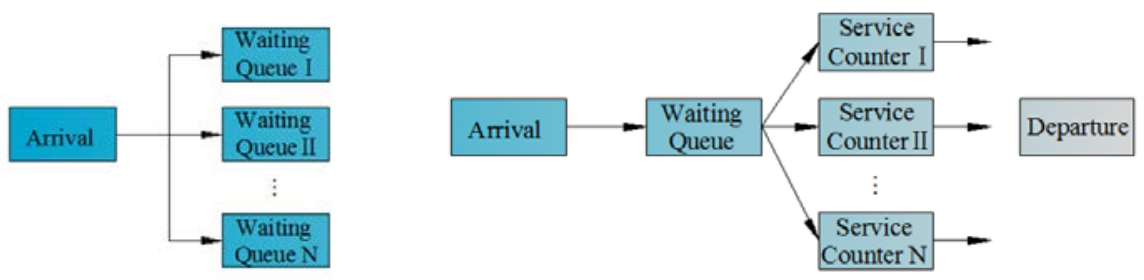

Fig. 2 Multi-service windows single queue waiting queuing model

\section{Erlang Queuing Model.}

Based on the complexity of the model solution, it can be proved that the approximate solution is close to the true solution when the order is low.

System utilization coefficient $\rho=\frac{r \lambda}{n \mu} \rho_{1}=\frac{r \lambda}{\mu}$,so $\rho_{1}=n \rho_{0}$.

The average arrival intensity of single queue $\mathrm{Er} / \mathrm{M} / 1$ model is $r \lambda$.

The average service rate of the system is $n \mu$.

Because the system does not limit the passenger source and the system capacity, the possible state set of the system should be $E=\{1,2,3, \cdots\}$.

It is obvious that the $\mathrm{R}$ algebra equation can be listed and the corresponding stationary distribution can be obtained.

$$
P_{i}= \begin{cases}\frac{n^{i} \rho^{i}}{i !} P_{0} & 0 \leq i \leq n \\ \frac{n^{n} \rho^{i}}{n !} P_{0} & i \geq n\end{cases}
$$

By the regularity condition $\sum P_{i}=1$, when $\beta<1$ the following equation can be drawn.

$$
P_{0}=\left[\sum_{i=0}^{n-1} \frac{\rho_{1}}{i !}+\frac{\rho_{1}}{n !(1-\rho)}\right]^{-1}
$$

Average waiting queue length:

$$
L_{q}=\frac{\rho_{i}^{n+1}}{(n-1) !\left(n-\rho_{1}\right)^{2}} P_{0}
$$

Average length of the system:

$$
L_{s}=L_{q}+\rho_{1}=\frac{\rho_{1}^{n+1}}{(n-1) !\left(n-\rho_{1}\right)^{2}} P_{0}+\rho_{1}
$$

The average sojourn time of passengers in the system can be obtained by Little formula:

$$
T_{s}=\frac{L_{s}}{r \lambda}
$$

Similarly, the average queuing time for travelers:

$$
T_{q}=\frac{L_{q}}{r \lambda}
$$

\section{Calculation of Practical Problems}

Combining with the experience of life, we analyze the safety check steps as follows. Passengers arrive at the airport in a random interval $\mathrm{T}$. When passengers arrive at Zone $\mathrm{A}$, because of personal interests__ less time for waiting, they are more inclined to choose the free service passengers to check in. If all service passengers are occupied when a passenger arrive, he/she would wait in line. 
Under this waiting circumstance, "he who comes firstly will be served firstly" is the principle adopted by the airport service system. Hence, passengers often choose to line in the shortest queue. Even though there are many service passengers for those who arrive at Zone A to choose from, zone A can still be considered equivalent to a large service window with regard to the same choice tendency. In this way, the queuing behavior of passengers can be determined as a single queue model with multiple service windows

Similarly, when passengers leave Zone A and enter Zone B, the characteristics are as above. So passengers queuing in Zone A, entering Zone B and leaving Zone C (Zone D is not included temporarily) can be seen as a system with 2 series (Zone A and Zone B). The service time of each zone is independent, and the negative exponential distribution is $\mathrm{r}$. Therefore, the total time $\mathrm{T}$ a customer spends in service obeys the order $r$ Erlangian distribution.

Table 1 For ordinary passengers

\begin{tabular}{|c|c|c|c|c|}
\hline $\begin{array}{c}\text { Mean residence } \\
\text { time in A area }\end{array}$ & $\begin{array}{c}\text { Average time } \\
\text { of X-Ray scan }\end{array}$ & $\begin{array}{c}\text { Average time of } \\
\text { Millimeter wave } \\
\text { scan }\end{array}$ & $\begin{array}{c}\text { Average time } \\
\text { on belt }\end{array}$ & $\begin{array}{c}\text { Passenger } \\
\text { flow }\end{array}$ \\
\hline $16.8168 \mathrm{~s}$ & $4.8194 \mathrm{~s}$ & $18.6289 \mathrm{~s}$ & $28.62 \mathrm{~s}$ & $4.73 /$ minute \\
\hline
\end{tabular}

Table 2 For the choice of Pre-check passengers

\begin{tabular}{|c|c|c|c|c|}
\hline $\begin{array}{c}\text { Mean residence } \\
\text { time in A area }\end{array}$ & $\begin{array}{c}\text { Average time } \\
\text { of X-Ray scan }\end{array}$ & $\begin{array}{c}\text { Average time of } \\
\text { Millimeter } \\
\text { wave scan }\end{array}$ & $\begin{array}{c}\text { Average time } \\
\text { on belt }\end{array}$ & $\begin{array}{c}\text { Passenger } \\
\text { flow }\end{array}$ \\
\hline $4.8204 \mathrm{~s}$ & $3.1039 \mathrm{~s}$ & $18.6289 \mathrm{~s}$ & $28.62 \mathrm{~s}$ & $6.64 /$ minute \\
\hline
\end{tabular}

\section{Conclusions}

Because Millimeter wave scanning and X-Ray door with get scanned property occur simultaneously, the time interval between passengers leaving Zone $C$ is the smaller value of the time of X-Ray Scan and Millimeter Wave Scan interval and the time of getting scanned property between two adjacent passengers.

As illustrated by the data we process with, the time of Millimeter wave scan and X-Ray scan is less than the time of getting scanned property. That is, after the completion of the manual inspection, passengers will be blocked in the Zone $\mathrm{C}$ conveyor exit waiting for goods on the conveyor belt. So Zone $\mathrm{C}$ is the bottleneck of airport security.

\section{References}

[1] Lu Chuanlai. Queuing theory [M]. Beijing: Beijing post and Telecommunications Press, 1994.

[2] Gong Guanglu, Qian Minping. Then application process [M]. Beijing: Tsinghua University press, 2004.

[3] Hart W. airport passenger terminal [Z]. Beijing: China Civil Aviation Administration infrastructure Airport Division / Airport Design Institute, 1989.

[4] Huaxing. Queuing theory and random service system [M]. Shanghai: Shanghai Translation Publishing Company, 1987.

[5] Sun Rongheng, Li Jianping. Queuing theory [M]. Beijing: Science Press, 2002

[6] Yu Zhiqing. Application of queuing theory in traffic engineering [J]. Journal of Zhongzhou University, 2005 (1):118-119.

[7] Liu Min, Yang Yuanxiang, Li Yinghong. A vacation queuing model based on signal intersection of lipstick and green light [J]. road traffic and safety, 2000 (8): 7- 9. 